\title{
Rede de Projeções por Inversão, Relações entre Tonnetze de Diferentes Tricordes
}

\author{
Inversional Projections Network, \\ Relationship between Tonnetze of Different Tricords
}

\section{Joel Albuquerque}

\author{
Universidade de São Paulo \\ joelalbuquerque@usp.br
}

\author{
Paulo de Tarso Salles \\ Universidade de São Paulo \\ ptsalles@usp.br
}

\begin{abstract}
Resumo: Esta é uma proposta metodológica para análise harmônica fundamentada em torno da inter-relação entre duas correntes inicialmente desenvolvidas para o estudo de obras pós-tonais: a teoria dos conjuntos (Straus, 2005; Solomon, 2005) e a teoria neorriemanniana (Lewin, 1982; Cohn, 2012). Seguimos aqui alguns apontamentos apresentados por Robert Morris (2007), recorrendo a matrizes de soma (teoria dos grupos) para a constatação de um padrão simétrico inerente ao corpo completo de relações entre as doze alturas, revelando o alinhamento entre diversas classes de conjuntos em torno de uma meta simetria, apresentada a seguir em diferentes perspectivas da rede de projeções por inversão. Outra possibilidade relevante desta nossa proposta foi a interação entre conjuntos harmônicos de diversas classes de intervalares e cardinalidades diferentes em um mesmo sistema. Propomos ainda alguns caminhos para a construção de redes de alturas (Tonnetze) não convencionais, apresentando desdobramentos de inversões a partir de diversas classes de conjuntos, não exclusivamente condicionados ao conjunto 3-11 (tricordes correspondentes às tríades maior e menor).
\end{abstract}

Palavras-chave: rede de projeções por inversão; Tonnetze de diferentes tricordes; teoria neoriemanianna; teoria dos conjuntos.

Abstract: This is a methodological proposal for harmonic analysis based on the relationship between two theoretical trends initially developed for the study of post-tonal music: set theory (Straus, 2005; Solomon, 2005) and neo-Riemannian theory (Lewin, 1982; Cohn, 2012). We also follow some concepts presented by Robert Morris (2007). We used sum matrices (group theory) to verify a symmetric pattern inherent to the complete body of relations betw een the tw elve tones, revealing the alignment between several set types around a meta-symmetry, presented in 
different perspectives of the inversional projection network. Another relevant possibility of our proposal is the interaction between set types of different cardinalities in the same system. We propose also some ways to build a non-conventional Tonnetze, showing inversions of several pitch classes, not exclusively based on the set 3-11 (major and minor trichords).

Keywords: inversional projections network; Tonnetze of different trichords; neo-Riemannian theory; musical set theory.

\section{1 - Introdução}

Refletindo sobre a afirmação do matemático Ian Stewatt (2012, p. 144) de que não devemos tomar a simetria como uma propriedade singular, totalitária uma única simetria - consideramos que existe uma pluralidade de simetrias inerentes a um mesmo grupo de alturas, que surgem de acordo com as diversas perspectivas que podemos revelar de um determinado contexto. Com isso constatamos que simetria e assimetria não são propriedades estanques e estratificadas; pelo contrário, são disposições interdependentes em que mesmo estruturas assimétricas em sua totalidade apresentam subconjuntos individualmente simétricos. Do mesmo modo, percebemos que conjuntos de notas não simétricos podem ser complementados com alturas adicionais $\mathrm{e}$ transformados em estruturas maiores simétricas em sua totalidade. Com isso, notamos que a mudança de cardinalidade entre grupos de alturas é um fator fundamental que destacaremos a seguir para entendermos esta inter-relação entre estruturas intervalares simétricas e assimétricas, disposições muito recorrentes no universo musical, destacadamente consideradas em práticas composicionais de obras vanguardistas do início do século XX.

$O$ resultado desta nossa investigação é a construção de um sistema de conexões entre conjuntos de diversas espécies e diferentes cardinalidades - que chamaremos neste trabalho de rede de projeções por inversão - relacionados a partir de subconjuntos simétricos implícitos e conjuntos maiores projetados por inversão e adição de alturas complementares, alinhados em torno de eixos de simetria invariantes. Partiremos, a princípio, da relação entre tricordes e tetracordes, mostrando a possibilidade de expansão deste sistema para a inclusão de estruturas maiores, complementado com pentacordes em uma segunda versão. Dentro desta proposta de construção da rede de projeções por inversão, apontaremos caminhos de discussão sobre a problemática inerente às pesquisas neorriemannianas tradicionais que apenas tratam da construção de sistemas que relacionam transposições e inversões de uma mesma classe de conjunto ou se 
pautam sobre redes de grupos de alturas com a mesma cardinalidade ${ }^{1}$. Outro interesse aqui é a busca de sistemas de organização harmônica que relacionem classes de conjuntos de toda espécie, incluindo também estruturas intervalares não convencionais, indo além das tradicionais tríades e tétrades previstas nas redes transformacionais da teoria neorriemanniana, e assim construir uma proposta de pesquisa que seja satisfatória para a análise e compreensão de procedimentos composicionais pertinentes ao repertório da música pós-tonal vanguardista do início do século XX e obras afins, entre os quais incluímos VillaLobos, cerne do nosso trabalho.

Apresentaremos assim duas possibilidades de construções da rede de projeções por inversão a partir de diferentes sequências de desdobramentos de grupos de alturas, mas ainda não esgotando todos os caminhos possíveis para este sistema, que provavelmente levam à inclusão de todas as classes de conjunto previstas no sistema de doze alturas.

\section{2 - Projeções de tetracordes simétricos}

Aplicaremos uma matriz de soma (teoria dos grupos²) (Tabela 1) para a tríade de Dó Maior (conjunto 3-11, numeração correspondente também para acordes menores), uma estrutura que não permite que seu grupo completo de três alturas $(\operatorname{Mod} 3)^{3}$ se alinhe em pares em torno de um mesmo eixo de soma (assimétrico em sua totalidade), mas que apresenta subconjuntos simétricos (três

1 Tomamos como referência as redes transformacionais entre "cubos" de inversões e transposições do conjunto 3-11 (tricordes correspondentes às tríades maior e menor), relacionados por tricordes do conjunto 3-12 (tríade aumentada) versus as "torres" de inversões e transposições dos conjuntos 4-27 (tétrades maior com sétima e meio diminuta) e 4-26 (tétrade menor com sétima), relacionadas por tetracordes do conjunto 4-28 (tétrade diminuta), dois sistemas com cardinalidades diferentes - módulo 3 e módulo 4, respectivamente - que são independentes e não relacionados dentro da teoria neorriemanniana tradicional (COHN, 2012). Em sua proposta de expansão para o segundo sistema, que relaciona tetracordes dos conjuntos 4-26, 4-27 e 4-28, Cohn (2012) inclui tetracordes do conjunto 4-25 (tétrade de sexta francesa). No entanto, percebemos que a cardinalidade em quatro entradas é reiterada e não há perspectiva para mudança de módulo.

${ }^{2}$ Campo da matemática especializada no estudo da simetria utilizando ferramentas algébricas conhecidas como matrizes de soma (ou multiplicação).

${ }^{3}$ Neste trabalho utilizaremos a tabela de Allen Forte que estabelece uma lista de classes de conjuntos de alturas, seguindo aqui parâmetros de análise pertinentes à teoria dos conjuntos. Trataremos por módulo " $\mathrm{n}$ " o número de itens recorrentes em um determinado grupo de alturas (por exemplo, módulo 7 para uma coleção com sete notas). Também utilizaremos a abreviação "Mod $n$ " e a nomenclatura "Mod $n \times \operatorname{Mod} n$ " para nos referirmos a inter-relação entre dois grupos de alturas específicos (por exemplo, Mod $4 \times$ Mod 4, fazendo referência a dois conjuntos de quatro entradas). 
pares de alturas (Mod2) e três notas isoladas (Mod1)) orientados por eixos distintos (Tabela 2).

\begin{tabular}{|c|c|c|c|}
\hline$(+)$ & Dó $(0)$ & Mi (4) & Sol (7) \\
\hline Dó (0) & 0 & 4 & 7 \\
\hline $\operatorname{Mi~}(4)$ & 4 & 8 & 11 \\
\hline Sol (7) & 7 & 11 & 2 \\
\hline
\end{tabular}

Tabela 1: Matriz de soma para o acorde Dó Maior

\begin{tabular}{c|ccc} 
Soma & Pares & Simetrias \\
\hline 0 & $0 / 0$ & $1-1$ \\
1 & - & - \\
2 & $7 / 7$ & $1-1$ \\
3 & - & - \\
4 & $0 / 4$ & $2-4$ \\
5 & - & - \\
6 & - & - \\
7 & $0 / 7$ & $2-5$ \\
8 & $4 / 4$ & $1-1$ \\
9 & - & - \\
10 & - & - \\
11 & $4 / 7$ & $2-3$ \\
\hline
\end{tabular}

Tabela 2: Subconjuntos simétricos implícitos no acorde Dó Maior e respectivos eixos

A tríade maior (assimétrica) pode ser transformada de modo a converterse em tetracorde simétrico - ou seja, com mudança de cardinalidade - a partir da escolha de um par de alturas de um de seus subconjuntos (díade). Identifica-se a soma dessa díade e agrega-se a altura adicional junto à nota restante da tríade. Essa operação resultará em um tetracorde simétrico. Para obter esta altura adicional, basta subtrair o valor de soma do eixo pelo valor da altura sem correspondente e teremos a nota compatível que completa a simetria do conjunto como um todo. Temos assim a seguinte fórmula: 
Sendo:

$$
\text { Altura }|x|+\text { Altura }|y|=\text { Soma }|s|(M o d 12)
$$

Então:

$$
\text { Soma }|s|-\text { Altura }|x|=\text { Altura }|y|(M o d 12)
$$

Considerando que o acorde maior (conjunto 3-11 (Mod3)) tem três pares de notas como subconjuntos simétricos (Mod2), cada qual orientado pelo seu respectivo eixo, poderemos estipular e adicionar uma nota correspondente para cada uma das alturas isoladas nos três casos, reiterando o mesmo valor de soma do respectivo eixo, projetando assim três possibilidades de tetracordes (Mod4) totalmente simétricos (Tabela 3 e Figura 1), originários da mesma tríade referida: os conjuntos 4-26 (acorde m7), 4-17 e 4-20 (acorde M7+).

\begin{tabular}{|c|c|c|c|}
\hline Soma $|s|$ & Altura $|x|$ & Altura $|y|=|s|-|x|$ & Projeção \\
\hline 4 & 7 & 9 & $4-26$ \\
\hline 7 & 4 & 3 & $4-17$ \\
\hline 11 & 0 & 11 & $4-20$ \\
\hline
\end{tabular}

Tabela 3: Projeção de tetracordes a partir de díades do acorde Dó Maior

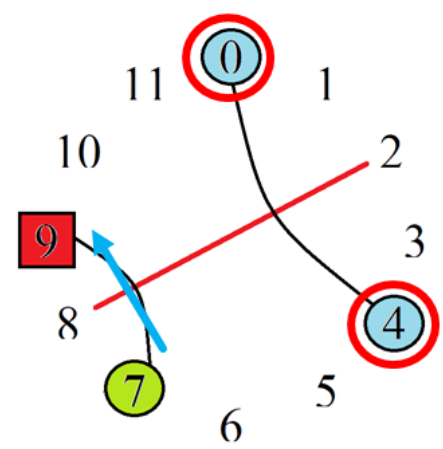

4-26

C $\ll$ Am

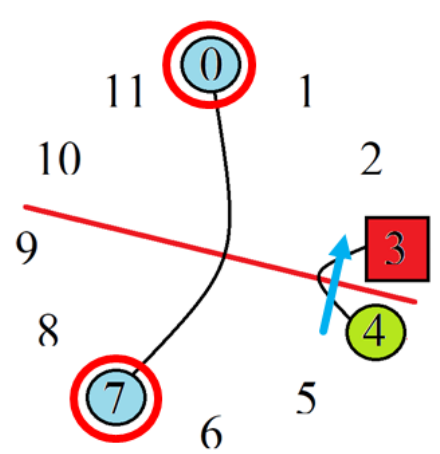

4-17

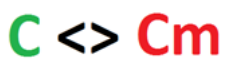

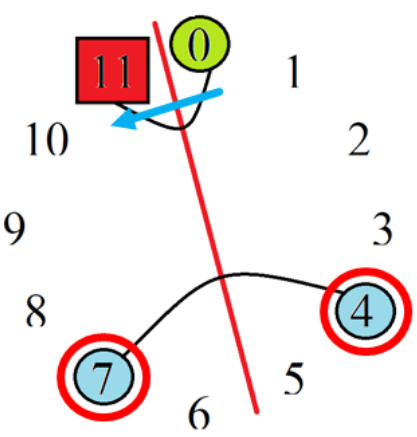

4-20

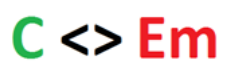

Figura 1: Projeção de tetracordes a partir de díades e inversões do acorde Dó Maior

Por sua vez, se substituirmos esta nota projetada por sua correspondente original, o resultado será a inversão do conjunto 3-11, gerando respectivam en te os acordes menores Am, Cm e Em (Tabela 4). Esta inversão da tríade maior em três acordes menores coincide com as transformações PRL da teoria neorriemanniana (Figura 2 e Figura 3), como podemos observar na Tonnetz 
convencional (Gollin, 1998, p. 197), em suas relações entre os três vértices do triângulo que representa o acorde de Dó Maior.

\begin{tabular}{|c|c|c|c|}
\hline Soma $|\mathrm{s}|$ & Altura $|\mathrm{x}|$ & Altura $|\mathrm{y}|=|\mathrm{s}-| \mathrm{x} \mid$ & Inversão \\
\hline 4 & 7 & 9 & $\mathrm{Am}$ \\
\hline 7 & 4 & 3 & $\mathrm{Cm}$ \\
\hline 11 & 0 & 11 & Em \\
\hline
\end{tabular}

Tabela 4: Inversão do acorde Dó Maior a partir de díades do tricorde

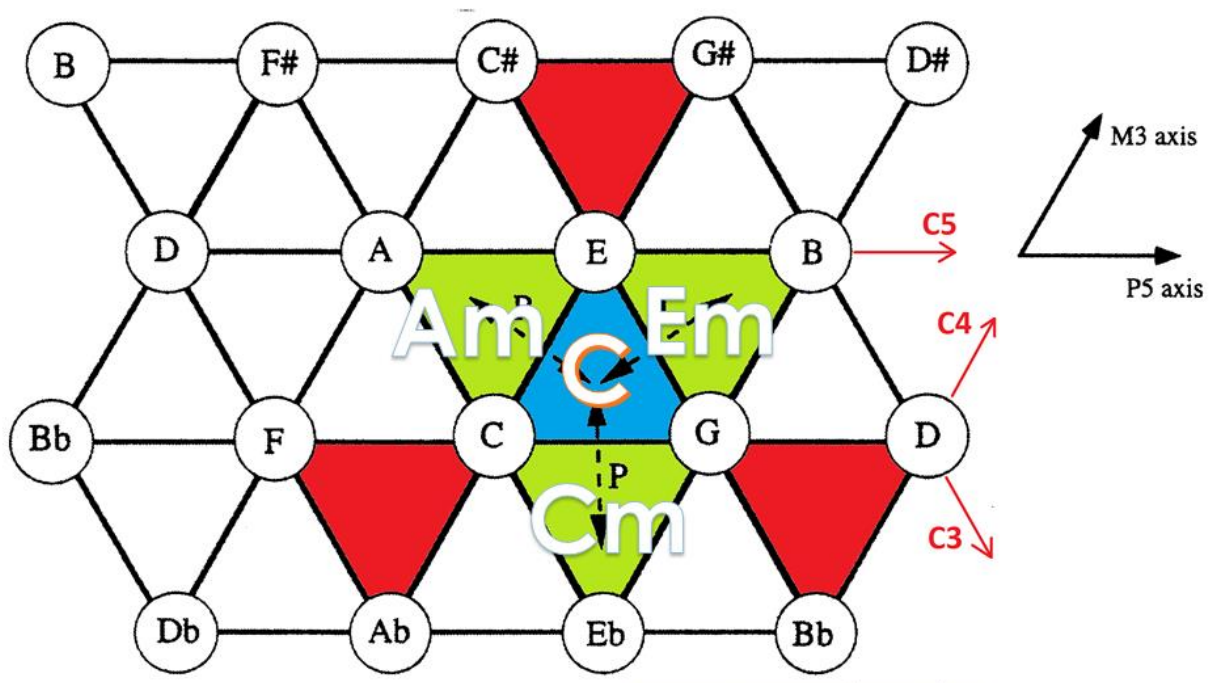

Figura 2: Inversões do acorde Dó Maior por díades, vértices dos triângulos que formam a Tonnetz, transformações PRL (Gollin, 1998, p. 197)
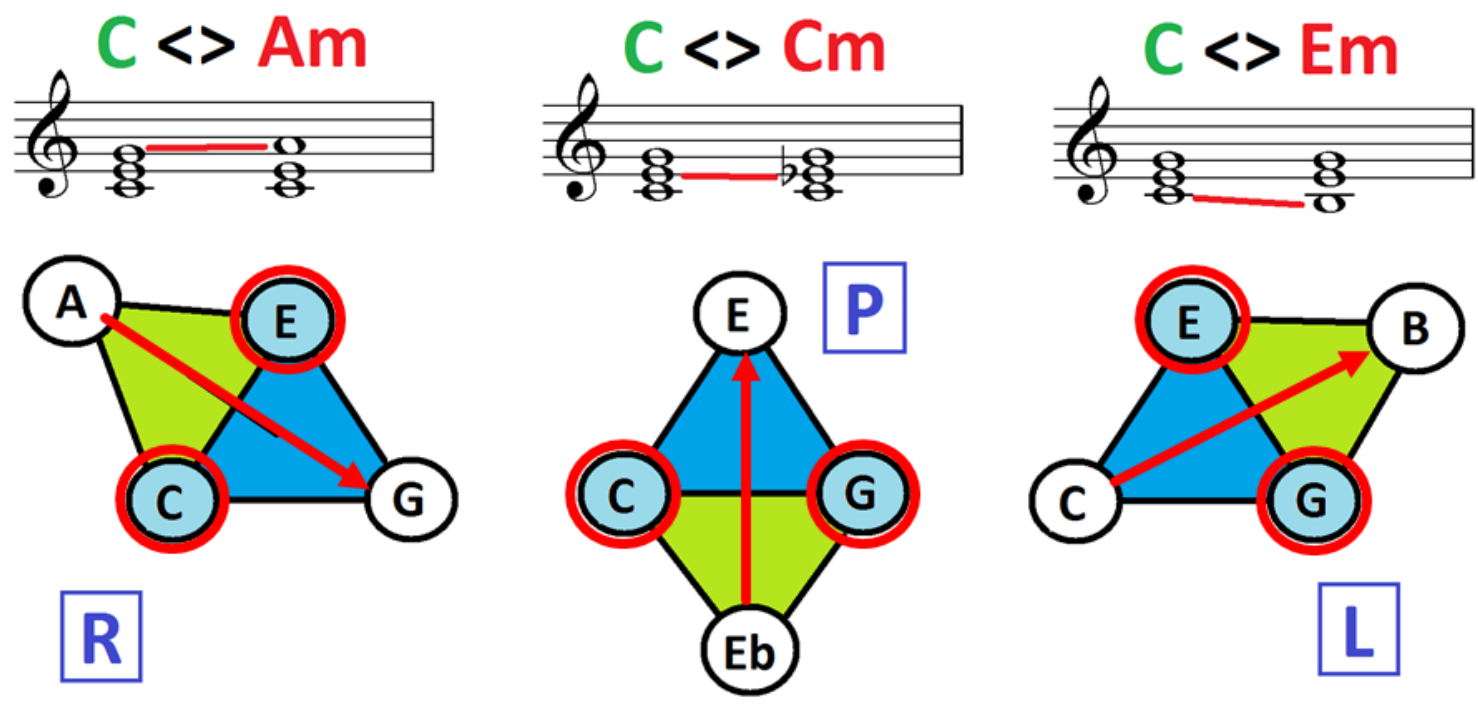

Figura 3: Inversão do acorde Dó Maior a partir de díades do tricorde, transformações PRL

\section{MUSICA THEORICA}


Percebemos que cada um deste tetracordes projetados a partir do acorde maior - 4-26, 4-17 e 4-20 - possui dois pares de altura orientados pelo mesmo eixo: o primeiro um subconjunto original do conjunto 3-11 e o segundo projetado como resultante da subtração do valor de soma do eixo do primeiro par pelo índice da altura isolada (altura $|y|=$ soma $|s|$ - altura $|x|$ ).
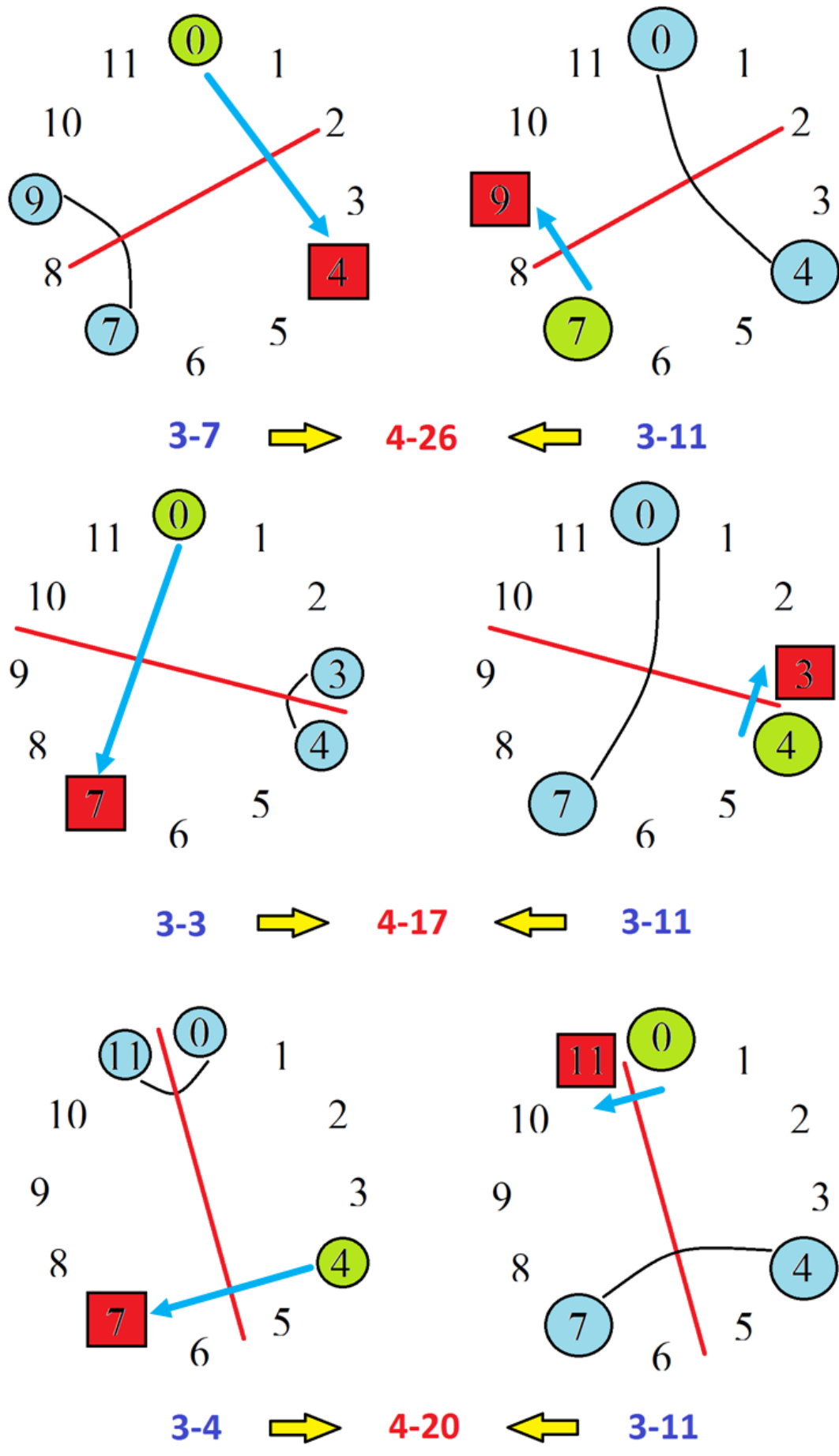

Figura 4: Pares de tricordes que podem projetar os tetracordes 4-26, 4-17 e 4-20 
Se reiterarmos o par gerado por projeção e transferirmos a relação de substituição agora para o primeiro par (subconjunto do acorde maior), teremos três novos tricordes que, quando invertidos, também geram estes tetracordes, prevendo as mesmas alturas e os mesmos eixos de simetria. Os tetracordes 4-26, 4-17 e 4-20 podem ser gerados não apenas a partir do conjunto 3-11 (acorde maior), mas também como projeções dos conjuntos 3-7, 3-3 e 3-4 respectivamen te. Podemos observar estas relações de inversão e projeção através das figuras abaixo (clockface) (Figura 4).

Temos assim um tricorde que pode projetar três tetracordes simétricos, os quais, por sua vez, podem ser gerados a partir de três classes de tricordes diferentes. Podemos expressar esta relação entre estes tricordes e tetracordes através de uma rede de conjuntos relacionados por projeções a partir de inversões, ou como chamaremos neste trabalho, uma rede de projeções por inversão (Figura 5). Temos aqui uma proposta de expansão do sistema de transformações PRL da teoria neorriemanniana, apresentando um sistema que não apenas relaciona tríades maiores e menores por inversão a partir do conjunto 3-11, como acontece em uma Tonnetz convencional, mas também propõe a construção de diferentes redes de alturas a partir de outras classes de conjuntos e relaciona-las em um único sistema. Isso nos permite ampliar significativamente a gama de caminhos harmônicos possíveis de serem mapeados, abrindo espaço para estruturas intervalares não convencionais que são recorrentes no universo pós-tonal, mas que ainda não haviam sido contempladas pela teoria neorriemanniana tradicional. Outra constatação importante é a possibilidade de relacionar classes de conjuntos de diferentes tipos e também de diferentes cardinalidades, neste caso, inter-relacionando tricordes (Mod3) e tetracordes (Mod4), aspecto também não previsto em uma Tonnetz convencional, que atende apenas grupos de três alturas de uma mesma classe de conjunto 3-11 (Gollin, 1998, p. 197). A correlação entre conjuntos de diferentes cardinalidades também não foi contemplada pela teoria transformacional (Cohn, 2012), uma vertente neorriemanniana posterior que se dedica à relação entre grupos com o mesmo número de alturas, avizinhados por um maior número de notas comuns e um deslocamento mínimo (semitom) entre suas variantes ("máxima parcimônia"), como é o caso da "dança dos cubos," que atende apenas tricordes, prioritariamente transposições e inversões do conjunto 3-11 (acordes maior e menor); e as "torres" de tetracordes, que preveem apenas conjuntos com quatro alturas, prioritariamente transposições e inversões do conjunto 4-27 (acordes maior com sétima e meio diminuto). 


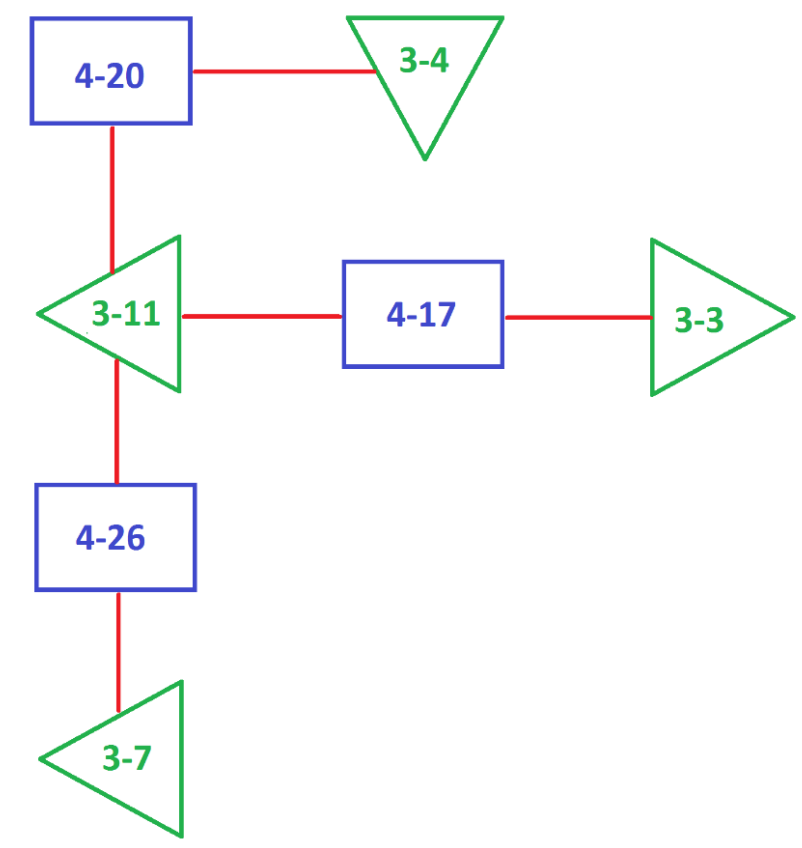

Figura 5: Rede de conjuntos relacionados por projeções e inversões

Esta relação entre o conjunto 3-11 e os tetracordes 4-17, 4-20 e 4-26 também aparece na construção da Tonnetz convencional, como podemos ver abaixo (Figura 6). Identificamos também que esta relação entre o conjunto 3-11 e os respectivos tetracordes acontece em torno da intersecção entre três sequências de classes de intervalares ${ }^{4}$ C3 (terça menor/sexta maior), C4 (terça maior/sexta menor) e C5 (quarta justa/quinta justa).

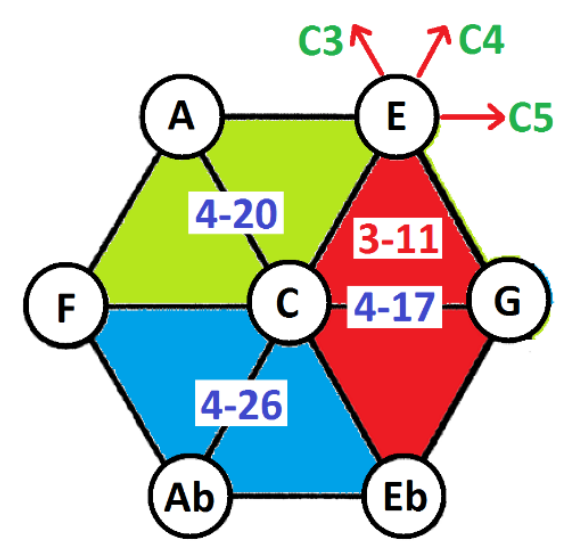

Figura 6: Tonnetz convencional para o conjunto 3-11

\footnotetext{
${ }^{4}$ Straus (2005) classifica seis possibilidades de ordens de classes de intervalos entre alturas: os ciclos intervalares C1 (segunda menor/sétima maior), C2 (segunda maior/sétima menor), C3 (terça menor/sexta maior), C4 (terça maior/sexta menor), C5 (quarta justa/quinta justa) e C6 (trítono). Neste trabalho ainda prevemos o ciclo intervalar $\mathrm{C} 0$, que trata da sequência de alturas em diferentes oitavas ou em uníssono, seguindo aqui conceitos da teoria dos ciclos proposto por George Perle (1977).
}

\section{MUSICA THEORICA}


Seguindo o mesmo raciocínio, percebemos que os tricordes 3-7, 3-3 e 3-4 também poderiam projetar outros tetracordes além dos citados 4-17, 4-20 e 4-26, já que cada tricorde projeta individualmente três tetracordes, fator que nos possibilitou ampliar nossa rede de projeções por inversão de tricordes (Figura 8 e Figura 13). Isto é possível de ser verificado quando construímos redes de alturas a partir dos tricordes em questão (conjuntos 3-7, 3-3 e 3-4; Figura 7), baseados aqui no princípio de construção de uma Tonnetz convencional (conjunto 3-11 (Mod3)). Surgem desta aplicação as relações entre o tricorde 3-3 e os tetracordes 4-3, 4-7 e 4-17 (ciclos intervalares C1, C3 e C4); entre o tricorde 3-4 e os tetracordes 4-7, 4-8 e 4-20 (ciclos intervalares C1, C4 e C5); e entre o tricorde 3-7 e os tetracordes 4-10, 4-23 e 4-26 (ciclos intervalares C2, C3 e C5).
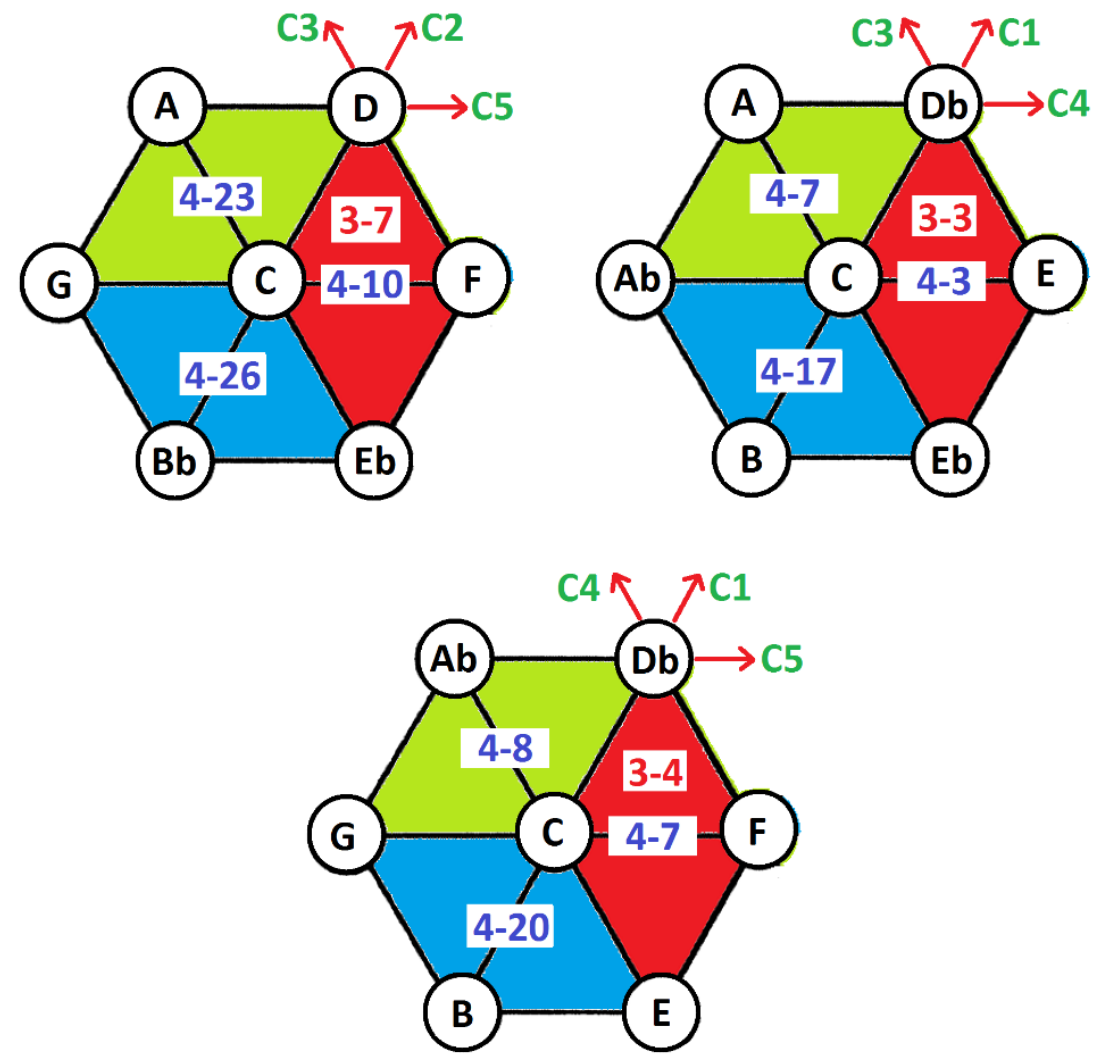

Figura 7: Tonnetze para os conjuntos 3-3, 3-4 e 3-7

Com estas novas informações podemos ampliar mais nossa rede de conjuntos relacionados por projeções e inversões (Figura 8). Esta construção se trata de um sistema de conexões entre Tonnetze distintos gerados a partir de diferentes tríades (Mod3), relacionados por subconjuntos de pares de alturas pertencentes aos conjuntos, estes representados pelos vértices dos triângulos que aparecem nas figuras. Nesta estrutura podemos perceber que cada tricorde se conecta com outros três tetracordes, sendo que estes conjuntos de quatro alturas, 
por sua vez, se relacionam apenas com dois tricordes cada. A partir desta constatação, seguimos ampliando esta rede de tricordes e tetracordes relacionados por projeções e inversões até encontrarmos seus extremos.

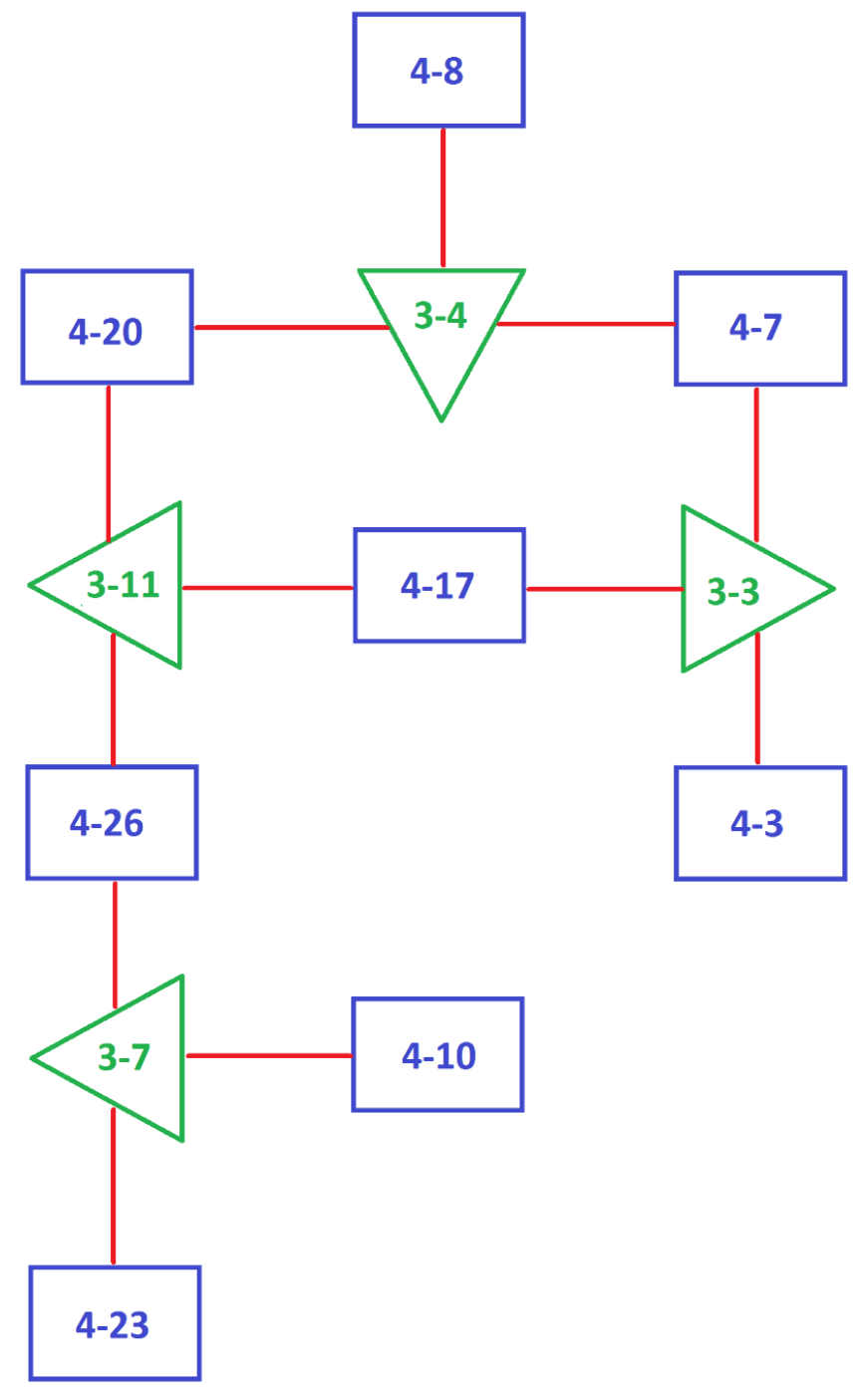

Figura 8: Rede de projeções por inversão ampliado

Este sistema pode ser ampliado ainda mais, considerando que os tetracordes 4-23, 4-10, 4-8 e 4-3 ainda permitem que cada um seja projetado por mais um tricorde. Considerando que cada um destes tetracordes está construído em torno de um eixo de soma que orienta dois pares de alturas, o primeiro um subconjunto reiterado e o segundo um par projetado a partir de uma nota isolada, inverteremos a relação de substituição e reiteração entre estes pares de alturas, a fim de identificar este segundo tricorde que permite projetar cada um destes quatro tetracordes por reflexão. Uma ferramenta pertinente para este propósito é o mostrador analógico (clockface) (Figura 9), no qual pudemos encontrar respectivamente os tricordes 3-9 para 4-23, 3-2 para 4-10 e 4-3, e 3-5 para 4-3. 

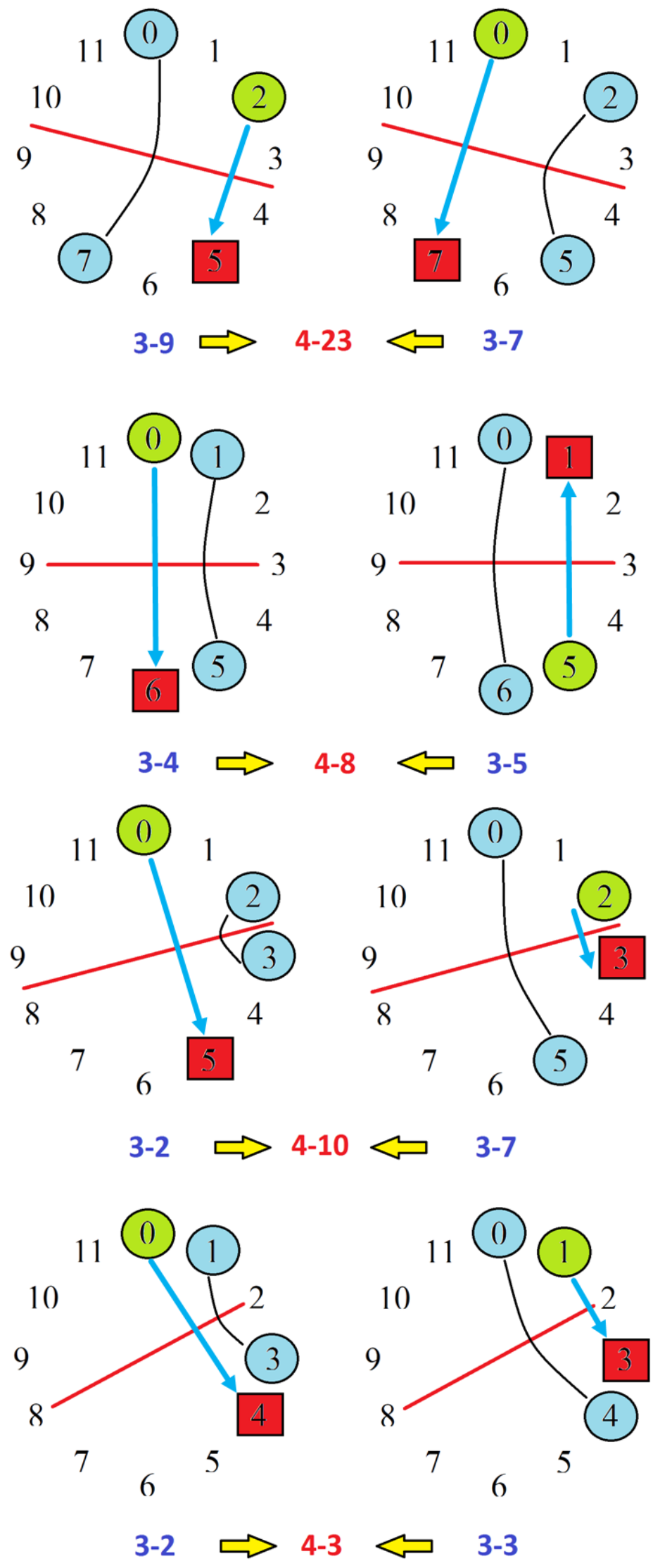

Figura 9: Pares de tricordes que podem projetar os tetracordes 4-3, 4-8, 4-10 e 4-23

\section{MUSICA THEORICA}


Os conjuntos de três alturas 3-9, 3-2 e 3-5 projetam novos tetracordes ainda não citados, lembrando novamente que cada tricorde projeta individualmente três tetracordes, seguindo com nossa ampliação da nossa rede de projeções por inversão. Construímos a Tonnetz para cada um destes tricordes em questão (conjuntos 3-9, 3-2 e 3-5; Figura 10). Surgem desta análise as relações entre o tricorde 3-9 e o tetracorde 4-23 (ciclos intervalares C2, C5 e C5); entre o tricorde 3-2 e os tetracordes 4-1, 4-3 e 4-10 (ciclos intervalares C1, C2 e C3); e entre o tricorde 3-5 e os tetracordes 4-8 e 4-9 (ciclos intervalares C1, C5 e C6).
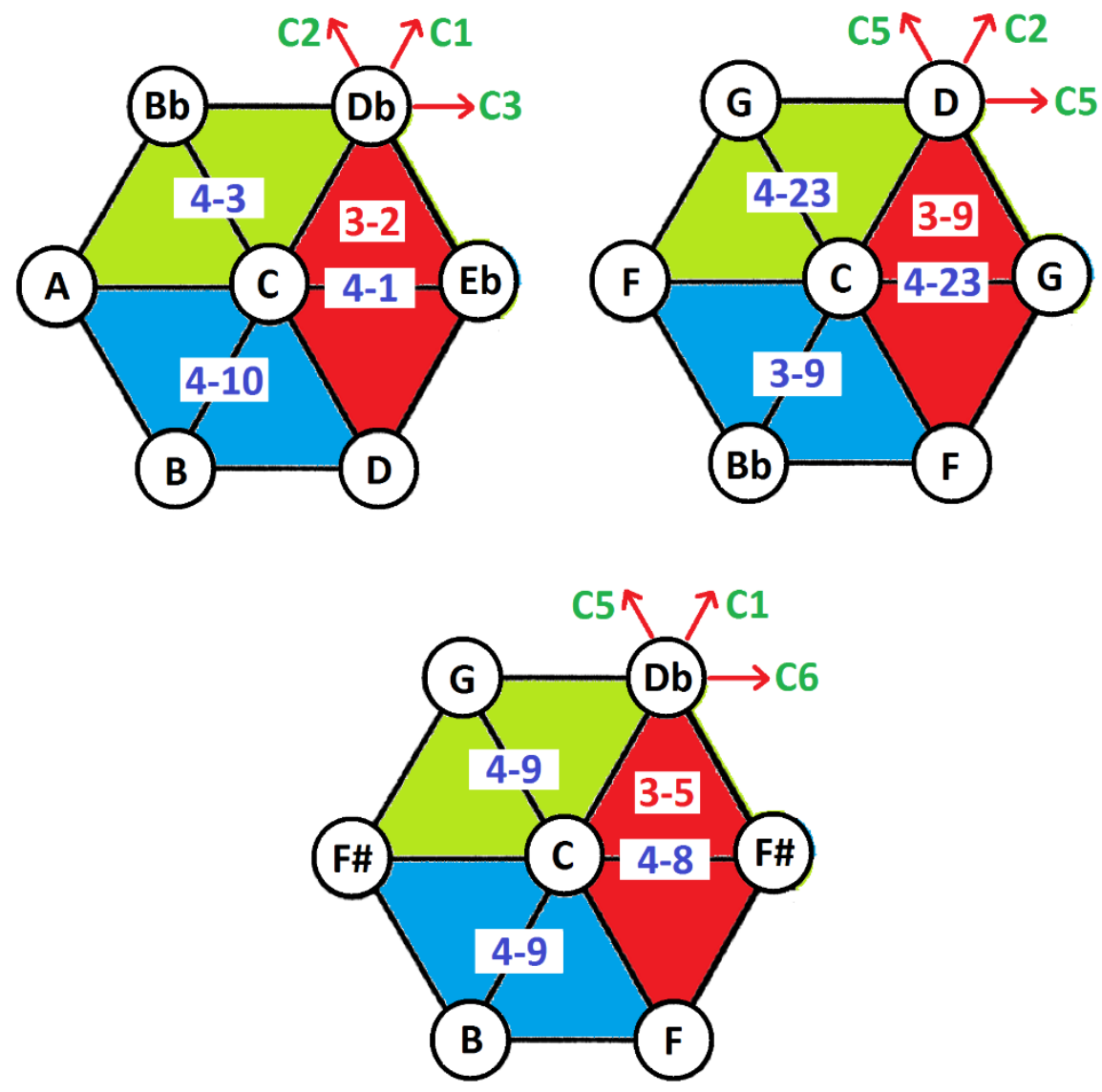

Figura 10: Tonnetze para os conjuntos 3-2, 3-5 e 3-9

Podemos verificar na figura anterior que o tetracorde 4-9 já não permite novas extensões de tricordes, pois se conecta duas vezes com o mesmo conjunto 3-5, limitando os desdobramentos deste sistema de projeções e inversões até este ponto. Por outro lado, o tricorde 3-9 se conecta duas vezes com o tetracorde 4-23 e uma vez consigo mesmo, não permitindo novas extensões. Faltaria ainda conhecer o segundo tricorde relacionado ao conjunto 4-1, que já adiantamos na figura ser o conjunto 3-1, com o qual mantém duas conexões. Esta constatação pode ser feita ao verificarmos a Tonnetz deste conjunto 3-1 (Figura 11, ciclos 
intervalares C1, C1 e C2) e da projeção no clockface dos dois tricordes que geram o tetracorde 4-1: os conjuntos 3-1 e 3-2 (Figura 12).

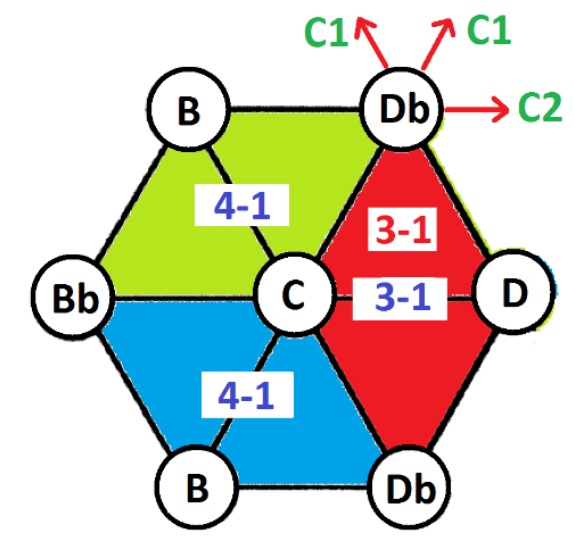

Figura 11: Tonnetz para o conjunto 3-1
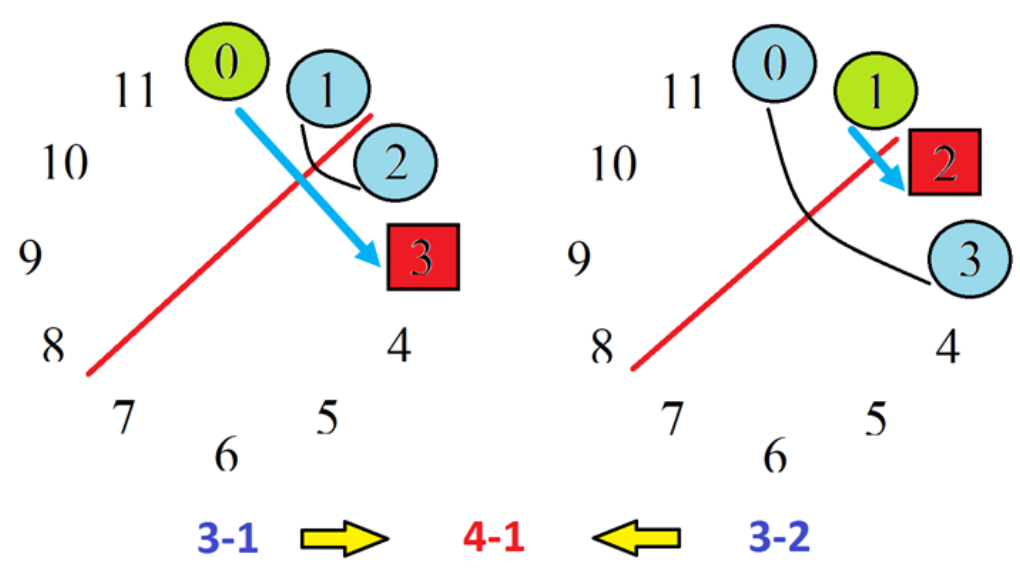

Figura 12: Pares de tricordes que podem projetar o tetracorde 4-1

O conjunto 3-1 também se relaciona consigo mesmo em sua terceira conexão, assim como vimos acontecer com o conjunto 3-9. Fechamos assim todos os caminhos de desdobramentos possíveis para este sistema de relações entre redes de alturas com tricordes. Chegamos então ao limite de desdobramentos desta estrutura que relaciona tricordes por projeções de tetracordes a partir de subconjuntos de pares de alturas (Figura 13). Podemos notar que a rede de projeções por inversão se trata de um sistema simétrico, espelhado em duas metades proporcionais de grupos de alturas que se correspondem. Trataremos mais adiante sobre outros detalhes inerentes a esta estrutura. 


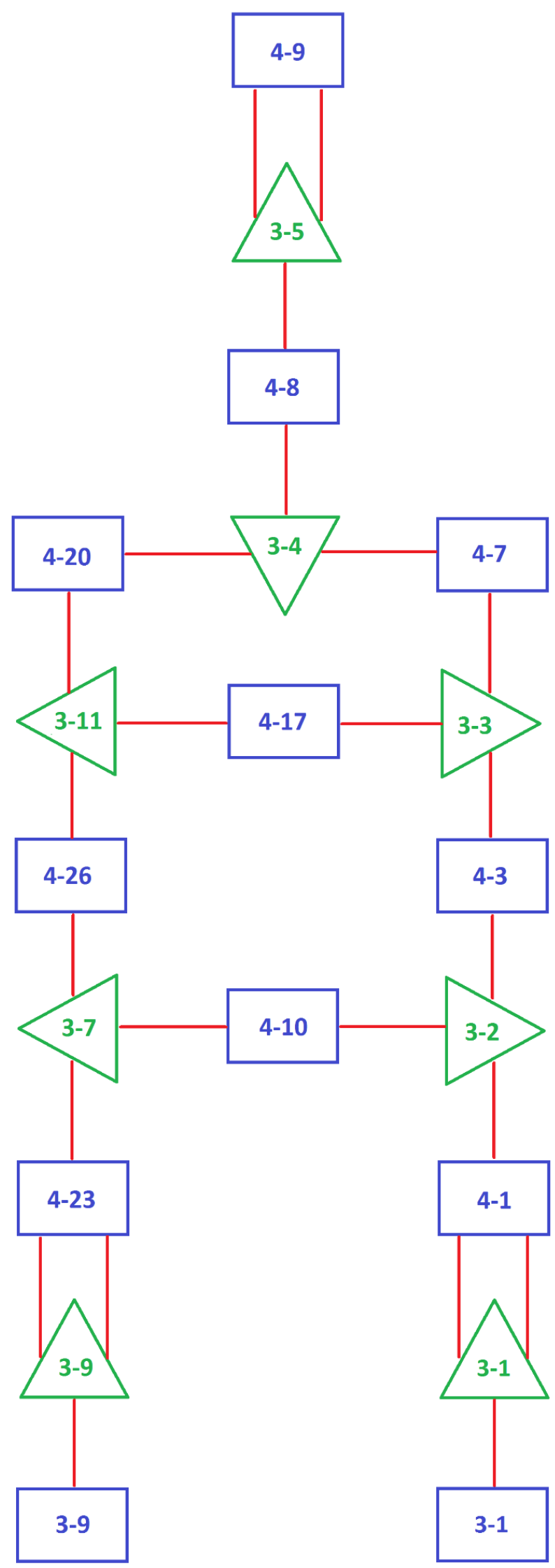

Figura 13: Rede de projeções por inversão de tricordes

\section{MUSICA THEORICA}

Revista da Associação Brasileira de Teoria e Análise Musical Journal of the Brazilian Society for Music Theory and Analysis @ TeMA 2016 - ISSN 2525-5541 


\section{3 - Projeções de pentacordes simétricos}

Voltando ao acorde maior, é possível também projetar outros três conjuntos simétricos em torno dos eixos que orientam os três subconjuntos de apenas uma altura (Mod1), acrescentando duas notas ao conjunto 3-11 em cada caso, gerando assim três possibilidades de pentacordes (Mod5) totalmente simétricos a partir da mesma tríade referida: os conjuntos 5-Z17, 5-22 e 5-34 (Tabela 5 e Figura 14).

\begin{tabular}{|c|c|c|c|}
\hline Soma $|s|$ & Altura $|x|$ & Altura $|y|=|s|-|x|$ & Projeção \\
\hline \multirow{2}{*}{0} & 4 & 8 & 5 5-z17 \\
\cline { 2 - 3 } & 7 & 4 & \\
\hline \multirow{2}{*}{8} & 0 & 8 & $5-22$ \\
\cline { 2 - 3 } & 7 & 1 & \multirow{2}{*}{5} \\
\hline \multirow{2}{*}{2} & 4 & 10 & \\
\cline { 2 - 3 } & 0 & 2 & \\
\hline
\end{tabular}

Tabela 5: Projeção de pentacordes a partir de alturas individuais do acorde Dó Maior

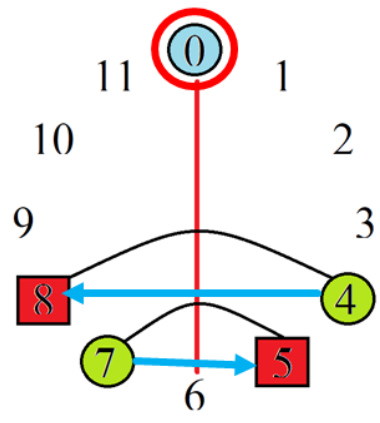

5-z17

$\mathrm{C} \ll \mathrm{Fm}$

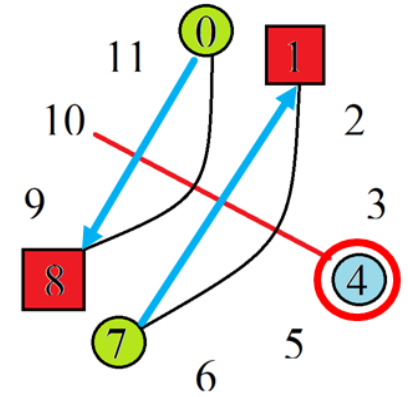

5-22

$\mathrm{C}<>\mathrm{CHm}$

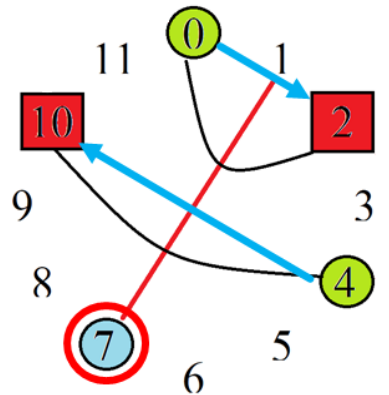

5-34

$\mathrm{C}<\mathrm{Gm}$

Figura 14: Projeção de pentacordes a partir de alturas individuais e inversões do acorde Dó Maior

Novamente, se substituirmos as duas notas projetadas pela soma por suas correspondentes originais, o resultado também será a inversão do conjunto 3-11, gerando respectivamente os acordes menores Fm, C\#m e Gm (Tabela 6). Esta segunda série de inversões da tríade maior em três acordes menores também coincidem com outras três transformações entre acordes que aparecem na Tonnetz, em suas relações entre as três arestas do triângulo que representa $\mathrm{o}$ acorde de Dó Maior (Figura 15 e Figura 16). 


\begin{tabular}{|c|c|c|c|}
\hline \multirow{2}{*}{ Soma $|\mathrm{s}|$} & Altura $|\mathrm{x}|$ & Altura $|\mathrm{y}|=|\mathrm{s}|-|\mathrm{x}|$ & Inversão \\
\hline \multirow{2}{*}{0} & 4 & 8 & \multirow{2}{*}{ Fm } \\
\cline { 2 - 3 } & 7 & 4 & \multirow{2}{*}{ C\#m } \\
\hline \multirow{2}{*}{8} & 0 & 8 & \multirow{2}{*}{ Gm } \\
\hline \multirow{2}{*}{2} & 7 & 1 & \\
\cline { 2 - 3 } & 4 & 2 & \multicolumn{2}{|c|}{} \\
\hline
\end{tabular}

Tabela 6: Inversão do acorde Dó Maior a partir de alturas individuais do tricorde

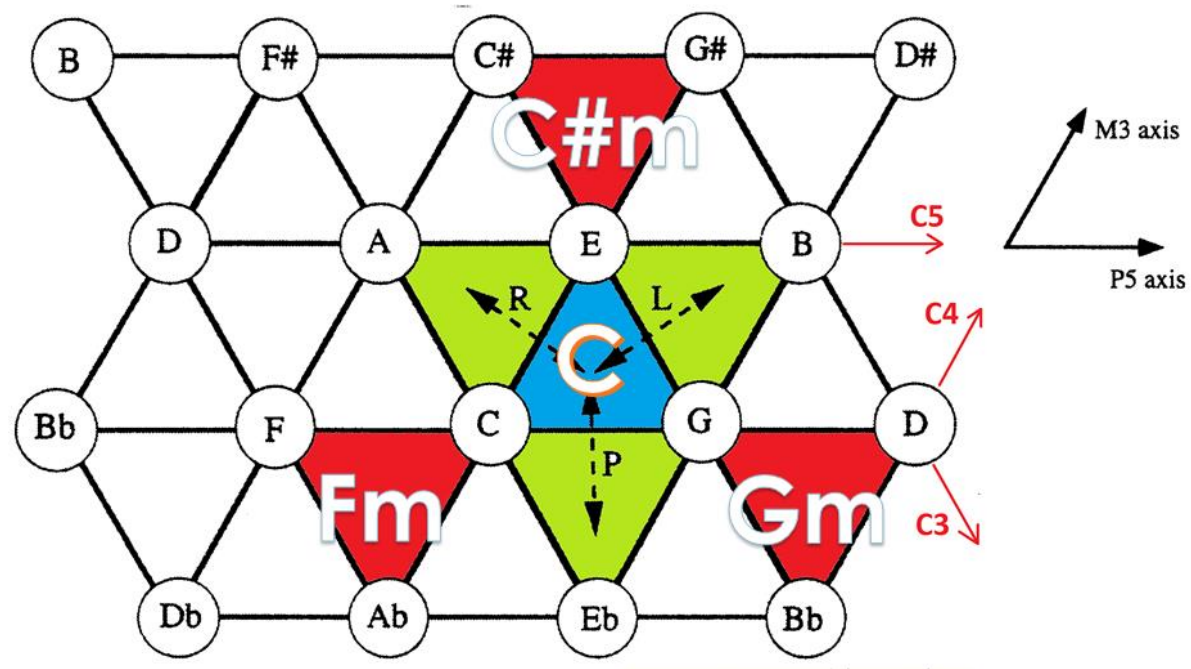

Figura 15: Inversões do acorde Dó Maior por alturas individuais, arestas dos triângulos que formam a Tonnetz
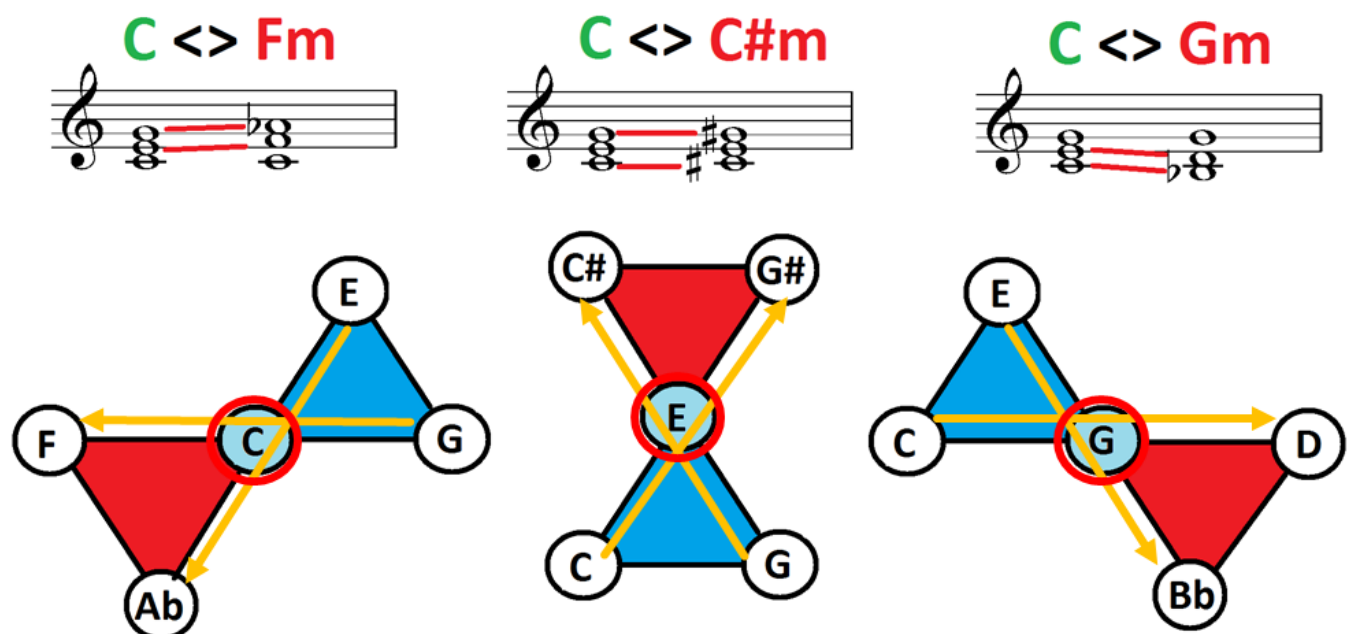

Figura 16: Inversão do acorde Dó Maior a partir de alturas individuais do tricorde

\section{MUSICA THEORICA}

Revista da Associação Brasileira de Teoria e Análise Musical Journal of the Brazilian Society for Music Theory and Analysis @ TeMA 2016 - ISSN 2525-5541 
Percebemos que cada um destes pentacordes projetados a partir do acorde maior - 5-Z17, 5-22 e 5-34 - possui dois pares de altura orientados pelo mesmo eixo, ambos projetados como resultantes da subtração do valor de soma do eixo invariante pelo índice da altura isolada (altura $|y|=$ soma $|s|$ - altura $|x|$ ), além da nota do subconjunto, que forma consigo mesma um terceiro par de mesma soma.
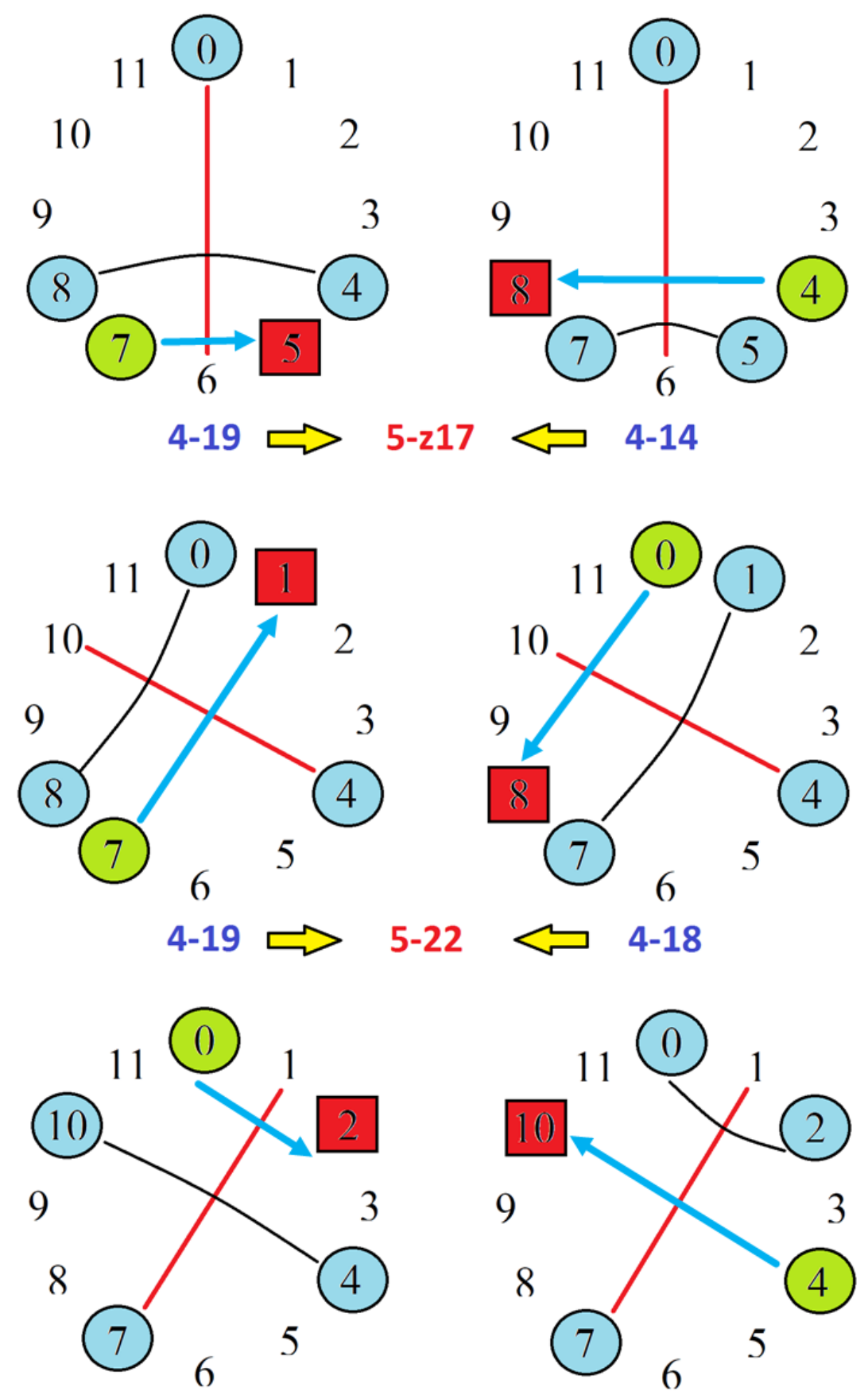

\section{4-27 $\Rightarrow 5-34 \longleftrightarrow$ 4-22}

Figura 17: Pares de tricordes que podem projetar os pentacordes 5-z17, 5-22 e 5-34 
Se reiterarmos a altura do subconjunto e um dos pares gerado por projeção, e transferirmos a relação de substituição para o outro par (e vice-ver sa), teremos dois novos tetracordes que, quando invertidos, também geram estes pentacordes, prevendo as mesmas alturas e os mesmos eixos de simetria. Os pentacordes 5-z17, 5-22 e 5-34 podem ser gerados não apenas a partir do conjunto 3-11 (acorde maior), mas também como projeções dos conjuntos 4-14 e 4-19 para 5-z17, 4-18e 4-19 para 5-22 e 4-27 e 4-22 para 5-34. Essas projeções podem ser verificadas nas figuras abaixo (clockface) (Figura 17).

É possível também projetar outros três conjuntos simétricos em torno dos eixos que orientam os três subconjuntos de apenas uma altura (Mod1) de cada um dos oito tricordes que formam a rede de projeções por inversão - 3-1, 3-2, 33, 3-4, 3-5, 3-7, 3-9 e 3-11 - acrescentando duas notas ao conjunto em cada caso, gerando assim três possibilidades de pentacordes (Mod5) totalmente simétricos a partir da mesma tríade referida (em alguns casos, tríades e tetracordes são projetadas, por conta de reiterações de alturas na inversão, como veremos a seguir).

Mapeamos nas tabelas abaixo (Tabela 7) cada uma destas possibilidades de projeção, observando na sequência: o conjunto referido, a altura escolhida como subconjunto (Mod1), a soma gerada em torno deste subconjunto, as demais alturas $|x|$ do tricorde e seus respectivos pares $|y|$ de mesma soma do eixo invariante e o conjunto do pentacorde projetado (tricorde ou tetracordes, em alguns casos). Na última coluna temos os dois tetracordes implícitos (ou tricordes, em alguns casos) que projetam o respectivo pentacorde, bastando apenas desconsiderar uma das alturas $|y|$ adicionais. A maioria desses tetracordes inerentes aos pentacordes são assimétricos (com exceção dos conjuntos 4-1 e 4-23), ao contrário dos tetracordes simétricos projetados a partir dos tricordes.

Conjunto 3-11, alturas [0,4,7] (acorde Dó Maior)

\begin{tabular}{|c|c|c|c|c|c|c|}
\hline $\begin{array}{c}\text { Subconjunto } \\
\text { (Mod1) }\end{array}$ & $\begin{array}{c}\text { Soma } \\
|s|\end{array}$ & $\begin{array}{c}\text { Altura } \\
|x|\end{array}$ & $\begin{array}{c}\text { Altura } \\
|y|\end{array}$ & $\begin{array}{c}\text { Projeção } \\
\text { pentacorde }\end{array}$ & \multicolumn{2}{|c|}{$\begin{array}{l}\text { Tetracordes } \\
\text { Implícitos }\end{array}$} \\
\hline \multirow[t]{2}{*}{0} & \multirow[t]{2}{*}{0} & 4 & 8 & \multirow{2}{*}{$\begin{array}{c}{[4,5,7,8,0]} \\
5-Z 17 \\
\end{array}$} & {$[0,4,5,7]$} & 4-14 \\
\hline & & 7 & 5 & & {$[4,7,8,0]$} & $4-19$ \\
\hline \multirow[t]{2}{*}{4} & \multirow[t]{2}{*}{8} & 0 & 8 & \multirow{2}{*}{$\begin{array}{c}{[0,1,4,7,8]} \\
5-22 \\
\end{array}$} & {$[4,7,8,0]$} & 4-19 \\
\hline & & 7 & 1 & & {$[0,1,4,7]$} & 4-18 \\
\hline \multirow[t]{2}{*}{7} & \multirow[t]{2}{*}{2} & 0 & 2 & \multirow{2}{*}{$\begin{array}{c}{[10,0,2,4,7]} \\
5-34\end{array}$} & {$[0,2,4,7]$} & 4-22 \\
\hline & & 4 & 10 & & {$[4,7,10,0]$} & $4-27$ \\
\hline
\end{tabular}


Conjunto 3-1, alturas $[0,1,2]$

\begin{tabular}{|c|c|c|c|c|c|c|}
\hline $\begin{array}{c}\text { Subconjunto } \\
\text { (Mod1) }\end{array}$ & $\begin{array}{c}\text { Soma } \\
|s|\end{array}$ & $\begin{array}{c}\text { Altura } \\
|x|\end{array}$ & $\begin{array}{c}\text { Altura } \\
|\mathrm{y}|\end{array}$ & $\begin{array}{c}\text { Projeção } \\
\text { pentacorde }\end{array}$ & \multicolumn{2}{|c|}{$\begin{array}{l}\text { Tetracordes } \\
\text { Implícitos }\end{array}$} \\
\hline \multirow[t]{2}{*}{0} & \multirow[t]{2}{*}{0} & 1 & 11 & \multirow{2}{*}{$\begin{array}{c}{[10,11,0,1,2]} \\
5-1 \\
\end{array}$} & {$[10,0,1,2]$} & 4-2 \\
\hline & & 2 & 10 & & {$[11,0,1,2]$} & 4-1 \\
\hline \multirow[t]{2}{*}{1} & \multirow[t]{2}{*}{2} & 0 & 2 & \multirow{2}{*}{$\begin{array}{c}{[0,1,2]} \\
3-1 \\
\end{array}$} & {$[0,1,2]$} & 3-1 \\
\hline & & 2 & 0 & & {$[0,1,2]$} & 3-1 \\
\hline \multirow[t]{2}{*}{2} & \multirow[t]{2}{*}{4} & 0 & 4 & \multirow{2}{*}{$\begin{array}{c}{[0,1,2,3,4]} \\
5-1\end{array}$} & {$[0,1,2,3]$} & 4-1 \\
\hline & & 1 & 3 & & {$[0,1,2,4]$} & 4-2 \\
\hline
\end{tabular}

Conjunto 3-2, alturas $[0,1,3]$

\begin{tabular}{|c|c|c|c|c|c|c|}
\hline $\begin{array}{c}\text { Subconjunto } \\
\text { (Mod1) }\end{array}$ & $\begin{array}{c}\text { Soma } \\
|s|\end{array}$ & $\begin{array}{c}\text { Altura } \\
|x|\end{array}$ & $\begin{array}{c}\text { Altura } \\
|y|\end{array}$ & $\begin{array}{c}\text { Projeção } \\
\text { pentacorde }\end{array}$ & \multicolumn{2}{|c|}{$\begin{array}{l}\text { Tetracordes } \\
\text { Implícitos }\end{array}$} \\
\hline \multirow[t]{2}{*}{0} & \multirow[t]{2}{*}{0} & 1 & 11 & \multirow{2}{*}{$\begin{array}{c}{[9,11,0,1,3]} \\
5-8\end{array}$} & {$[9,0,1,3]$} & 4-12 \\
\hline & & 3 & 9 & & {$[11,0,1,3]$} & 4-2 \\
\hline \multirow[t]{2}{*}{1} & \multirow[t]{2}{*}{2} & 0 & 2 & \multirow{2}{*}{$\begin{array}{c}{[11,0,1,2,3]} \\
5-1\end{array}$} & {$[11,0,1,3]$} & $4-2$ \\
\hline & & 3 & 11 & & {$[0,1,2,3]$} & 4-1 \\
\hline \multirow[t]{2}{*}{3} & \multirow[t]{2}{*}{6} & 0 & 6 & \multirow{2}{*}{$\begin{array}{c}{[0,1,3,5,6]} \\
5-z 12 \\
\end{array}$} & {$[0,1,3,5]$} & 4-11 \\
\hline & & 1 & 5 & & {$[0,1,3,6]$} & $4-13$ \\
\hline
\end{tabular}

Conjunto 3-3, alturas $[0,1,4]$

\begin{tabular}{|c|c|c|c|c|c|c|}
\hline $\begin{array}{c}\text { Subconjunto } \\
\text { (Mod1) }\end{array}$ & $\begin{array}{c}\text { Soma } \\
|s|\end{array}$ & $\begin{array}{c}\text { Altura } \\
|x|\end{array}$ & $\begin{array}{c}\text { Altura } \\
|y|\end{array}$ & $\begin{array}{c}\text { Projeção } \\
\text { pentacorde }\end{array}$ & \multicolumn{2}{|c|}{$\begin{array}{l}\text { Tetracordes } \\
\text { Implícitos }\end{array}$} \\
\hline \multirow[t]{2}{*}{0} & \multirow[t]{2}{*}{0} & 1 & 11 & \multirow{2}{*}{$\begin{array}{c}{[8,11,0,1,4]} \\
5-z 37\end{array}$} & {$[0,1,4,8]$} & 4-19 \\
\hline & & 4 & 8 & & {$[11,0,1,4]$} & $4-4$ \\
\hline \multirow[t]{2}{*}{1} & \multirow[t]{2}{*}{2} & 0 & 2 & \multirow{2}{*}{$\begin{array}{c}{[10,0,1,2,4]} \\
5-8\end{array}$} & {$[10,0,1,4]$} & 4-12 \\
\hline & & 4 & 10 & & {$[0,1,2,4]$} & 4-2 \\
\hline \multirow[t]{2}{*}{4} & \multirow[t]{2}{*}{8} & 0 & 8 & \multirow{2}{*}{$\begin{array}{c}{[0,1,4,7,8]} \\
5-22\end{array}$} & {$[0,1,4,7]$} & 4-18 \\
\hline & & 1 & 7 & & {$[0,1,4,8]$} & $4-19$ \\
\hline
\end{tabular}


Conjunto 3-4, alturas $[0,1,5]$

\begin{tabular}{|c|c|c|c|c|c|c|}
\hline $\begin{array}{c}\text { Subconjunto } \\
\text { (Mod1) }\end{array}$ & $\begin{array}{c}\text { Soma } \\
|s|\end{array}$ & $\begin{array}{c}\text { Altura } \\
|x|\end{array}$ & $\begin{array}{c}\text { Altura } \\
|y|\end{array}$ & $\begin{array}{c}\text { Projeção } \\
\text { pentacorde }\end{array}$ & \multicolumn{2}{|c|}{$\begin{array}{l}\text { Tetracordes } \\
\text { Implícitos }\end{array}$} \\
\hline \multirow[t]{2}{*}{0} & \multirow[t]{2}{*}{0} & 1 & 11 & \multirow{2}{*}{$\begin{array}{c}{[11,0,1,5,7]} \\
5-15 \\
\end{array}$} & {$[0,1,5,7]$} & $4-16$ \\
\hline & & 5 & 7 & & {$[7,11,0,1]$} & 4-5 \\
\hline \multirow[t]{2}{*}{1} & \multirow[t]{2}{*}{2} & 0 & 2 & \multirow{2}{*}{$\begin{array}{c}{[9,0,1,2,5]} \\
5-z 37 \\
\end{array}$} & {$[9,0,1,5]$} & 4-19 \\
\hline & & 5 & 9 & & {$[0,1,2,5]$} & $4-4$ \\
\hline \multirow[t]{2}{*}{5} & \multirow[t]{2}{*}{10} & 0 & 10 & \multirow{2}{*}{$\begin{array}{c}{[9,10,0,1,5]} \\
5-z 17\end{array}$} & {$[9,0,1,5]$} & 4-19 \\
\hline & & 1 & 9 & & {$[10,0,1,5]$} & $4-14$ \\
\hline
\end{tabular}

Conjunto 3-5, alturas $[0,1,6]$

\begin{tabular}{|c|c|c|c|c|c|c|}
\hline $\begin{array}{l}\text { Subconjunto } \\
\text { (Mod1) }\end{array}$ & $\begin{array}{c}\text { Soma } \\
|s|\end{array}$ & $\begin{array}{l}\text { Altura } \\
|x|\end{array}$ & $\begin{array}{l}\text { Altura } \\
|y|\end{array}$ & $\begin{array}{c}\text { Projeção } \\
\text { pentacorde }\end{array}$ & \multicolumn{2}{|c|}{$\begin{array}{l}\text { Tetracordes } \\
\text { Implícitos }\end{array}$} \\
\hline \multirow[t]{2}{*}{0} & \multirow[t]{2}{*}{0} & 1 & 11 & \multirow{2}{*}{$\begin{array}{c}{[11,0,1,6]} \\
4-6 \\
\end{array}$} & {$[0,1,6]$} & $3-5$ \\
\hline & & 6 & 6 & & {$[11,0,1,6]$} & $4-6$ \\
\hline \multirow[t]{2}{*}{1} & \multirow[t]{2}{*}{2} & 0 & 2 & \multirow{2}{*}{$\begin{array}{c}{[0,1,2,6,8]} \\
5-15 \\
\end{array}$} & {$[6,8,0,1]$} & $4-16$ \\
\hline & & 6 & 8 & & {$[0,1,2,6]$} & $4-5$ \\
\hline \multirow[t]{2}{*}{6} & \multirow[t]{2}{*}{0} & 0 & 0 & \multirow{2}{*}{$\begin{array}{c}{[11,0,1,6]} \\
4-6\end{array}$} & {$[0,1,6]$} & $3-5$ \\
\hline & & 1 & 11 & & {$[11,0,1,6]$} & $4-6$ \\
\hline
\end{tabular}

Conjunto 3-7, alturas $[0,2,5]$

\begin{tabular}{|c|c|c|c|c|c|c|}
\hline $\begin{array}{c}\text { Subconjunto } \\
\text { (Mod1) }\end{array}$ & $\begin{array}{c}\text { Soma } \\
|\mathrm{s}|\end{array}$ & $\begin{array}{c}\text { Altura } \\
|\mathrm{x}|\end{array}$ & $\begin{array}{c}\text { Altura } \\
|\mathrm{y}|\end{array}$ & $\begin{array}{c}\text { Projeção } \\
\text { pentacorde }\end{array}$ & \multicolumn{2}{|c|}{$\begin{array}{l}\text { Tetracordes } \\
\text { Implícitos }\end{array}$} \\
\hline \multirow[t]{2}{*}{0} & \multirow[t]{2}{*}{0} & 2 & 10 & \multirow{2}{*}{$\begin{array}{c}{[10,0,2,5,7]} \\
5-35 \\
\end{array}$} & {$[0,2,5,7]$} & $4-23$ \\
\hline & & 5 & 7 & & {$[10,0,2,5]$} & $4-22$ \\
\hline \multirow[t]{2}{*}{2} & \multirow[t]{2}{*}{4} & 0 & 4 & \multirow{2}{*}{$\begin{array}{c}{[11,0,2,4,5]} \\
5-z 12\end{array}$} & {$[0,2,4,5]$} & 4-11 \\
\hline & & 5 & 11 & & {$[11,0,2,5]$} & $4-13$ \\
\hline \multirow[t]{2}{*}{5} & \multirow[t]{2}{*}{10} & 0 & 10 & \multirow{2}{*}{$\begin{array}{c}{[8,10,0,2,5]} \\
5-34\end{array}$} & {$[0,2,5,8]$} & $4-27$ \\
\hline & & 2 & 8 & & {$[10,0,2,5]$} & $4-22$ \\
\hline
\end{tabular}


Conjunto 3-9, alturas $[0,2,7]$

\begin{tabular}{|c|c|c|c|c|c|c|}
\hline $\begin{array}{c}\text { Subconjunto } \\
\text { (Mod1) }\end{array}$ & $\begin{array}{c}\text { Soma } \\
|s|\end{array}$ & $\begin{array}{c}\text { Altura } \\
|x|\end{array}$ & $\begin{array}{c}\text { Altura } \\
|y|\end{array}$ & $\begin{array}{c}\text { Projeção } \\
\text { pentacorde }\end{array}$ & \multicolumn{2}{|c|}{$\begin{array}{l}\text { Tetracordes } \\
\text { Implícitos }\end{array}$} \\
\hline \multirow[t]{2}{*}{0} & \multirow[t]{2}{*}{0} & 2 & 10 & \multirow{2}{*}{$\begin{array}{c}{[10,0,2,5,7]} \\
5-35\end{array}$} & {$[0,2,5,7]$} & $4-23$ \\
\hline & & 7 & 5 & & {$[7,10,0,2]$} & $4-22$ \\
\hline \multirow[t]{2}{*}{2} & \multirow[t]{2}{*}{4} & 0 & 4 & \multirow{2}{*}{$\begin{array}{c}{[0,2,4,7,9]} \\
5-35 \\
\end{array}$} & {$[7,9,0,2]$} & $4-23$ \\
\hline & & 7 & 9 & & {$[0,2,4,7]$} & 4-22 \\
\hline \multirow[t]{2}{*}{7} & \multirow[t]{2}{*}{2} & 0 & 2 & \multirow{2}{*}{$\begin{array}{c}{[0,2,7]} \\
3-9\end{array}$} & {$[0,2,7]$} & $3-9$ \\
\hline & & 2 & 0 & & {$[0,2,7]$} & $3-9$ \\
\hline
\end{tabular}

Tabela 7: Possibilidades de projeções a partir de alturas individuais dos conjuntos 3-1, $3-2,3-3,3-4,3-5,3-7,3-9$ e $3-11$

A partir do levantamento destes dados, podemos ampliar nosso sistema de projeções por inversões, que apenas relacionava tetracordes (Mod4) projetados a partir de díades de alturas (Mod2) subconjuntos de tricordes (Mod3). Incluiremos agora a relação entre pentacordes projetados a partir de alturas avulsas (Mod1) subconjuntos dos mesmos tricordes, estes representados pelas arestas dos triângulos que aparecem nas figuras, acrescentando também os tetracordes e tricordes implícitos que projetam os mesmos pentacordes. Nesta estrutura podemos perceber que cada tricorde se conecta com outros seis conjuntos projetados por inversão: três em torno de suas vértices e três em torno de suas arestas. A partir desta constatação, seguimos ampliando esta rede de conjuntos relacionados por projeções a partir de inversões, como podemos verificar na figura abaixo (Figura 18). 


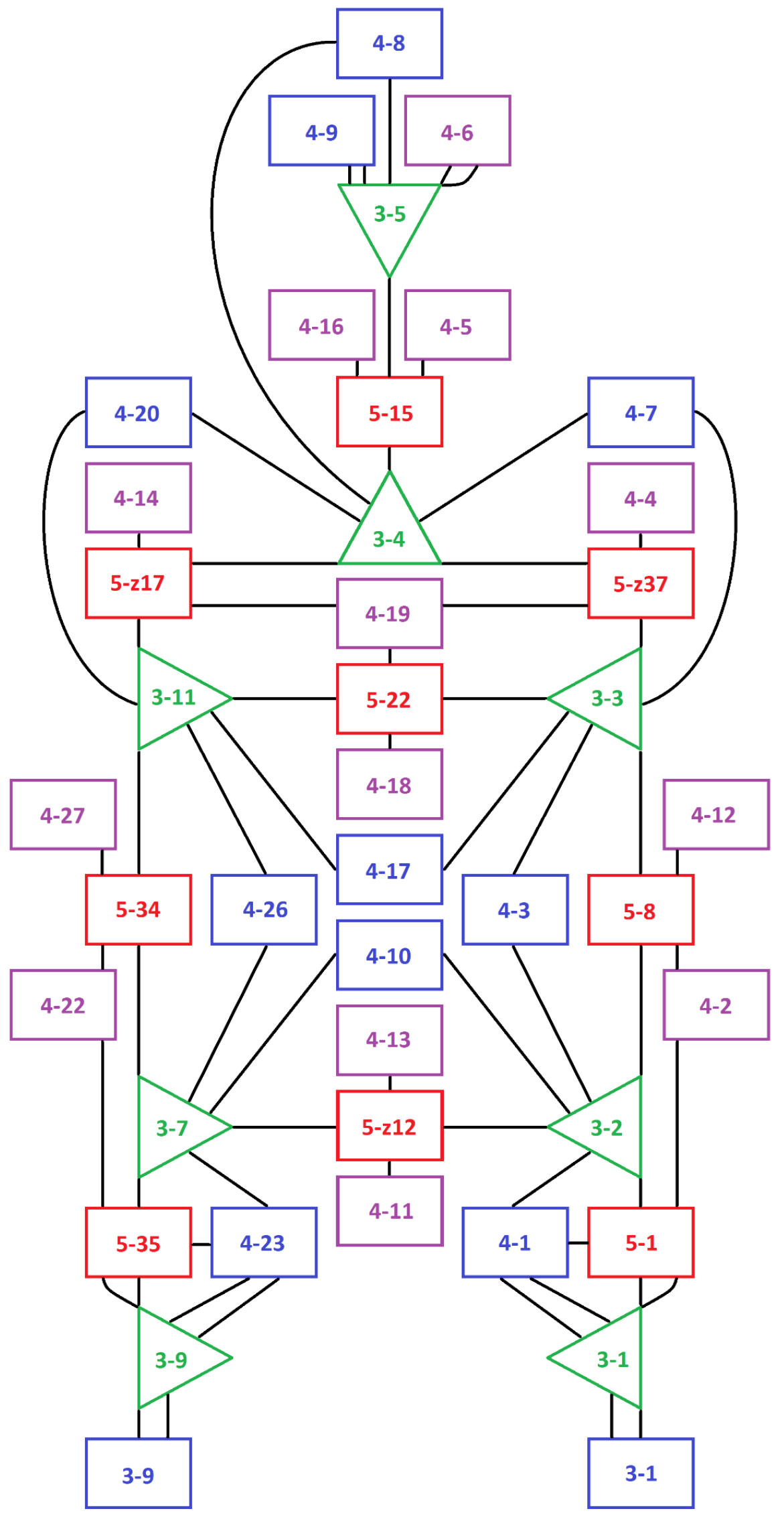

Figura 18: Ampliação da rede de projeções por inversão de tricordes

\section{MUSICA THEORICA}

Revista da Associação Brasileira de Teoria e Análise Musical Journal of the Brazilian Society for Music Theory and Analysis @ TeMA 2016 - ISSN 2525-5541 
Podemos perceber que esta grande estrutura de quarenta e dois conjuntos relacionados por projeções a partir de inversões apresenta propriedades simétricas em diversos níveis, com destaque para a equivalência entre os dois grandes grupos de treze conjuntos cada que estão nas laterais esquerda e direita da figura. Ambos os grupos se correspondem verticalmente em número de conjuntos, conjuntos com o mesmo índice de alturas em posições similares e conexões idênticas entre os elementos que configuram cada estrutura. Outra característica importante é que nas extremidades onde se limitam os desdobramentos de cada grupo (na parte inferior da figura) temos três conjuntos equivalentes que são recordes de ciclos intervalares: C5 (ordem da classe de intervalo $^{5}|5|$ ) à esquerda (conjuntos 3-9, 4-23 e 5-35) e C1 (ordem da classe de intervalo |1|) à direita (conjuntos 3-1, 4-1 e 5-1). Esta disposição nos faz perceber que cada estrutura é construída a partir de inversões e projeções a partir dos ciclos intervalares $\mathrm{C} 5$ e C1.

\section{Referencias}

1. Cohn, Richard. 2012. Audacious Euphony: Chromatic Harmony and the Triad's Second Nature. New York: Oxford University Press.

2. Gollin, Edward. 1998. Some Aspects of Three-Dimensional Tonnetze. Journal of Music Theory, Vol. 42, nº 2, p. 195-206.

3. Lewin, David. 1982. A Formal Theory of Generalized Tonal Functions. Journal of Music Theory, Vol. 26, No. 1, p. 23-60.

4. Morris, Robert. 1982. Review of John Rahn's Basic Atonal Theory (1980). Music Theory Spectrum, Vol. 4, p. 138-154.

5 . 2007. Mathematics and the Twelve-Tone System: Past, Present, and Future. Perspectives of New Music, Vol. 45, No. 2, p. 76-107.

6. Oliveira, João Pedro Paiva. 2007. Teoria analítica da música do século XX. Lisboa: Calouste Gulbenkian.

7. Perle, George. 1977. Twelve-tone Tonality. Berkeley: University of California Press.

\footnotetext{
${ }^{5}$ Identificaremos classes de intervalo entre duas barras verticais (Oliveira, 2007).
} 
8. Rahn, John. 1980. Basic Atonal Theory. New York: Longman.

9. Solomon, Larry. 2005. The Table of Pitch Class Sets. Disponível em: http://solomonsmusic.net/pcsets.htm

10. Straus, Joseph N. 2005. Introduction to Post Tonal Theory. $3^{\underline{a}}$ ed. Upper Saddle River: Prentice-Hall.

11. Stewart, Ian. 2012. Uma História da Simetriana Matemática. Rio de Janeiro: Jorge Zahar. 